the magnetic equator and describing a circular orbit concentric with the earth. The magnetic force due to the earth's magnetic field is directed towards the north, and the deflecting force must be directed towards the centre to keep the corpuscle in its orbit. Applying the well-known rule for electromagnetic deflection, we find that the corpuscle, if negative, must move from west to east.

The question regarding the simultaneity of the occurrence of the positive equatorial storms is a very important one for their physical explanation, for if it takes a time of several minutes for the pulse to travel round the earth, we must suppose that the currents producing the effects are near the earth compared with its diameter, while simultaneity of beginning would indicate very distant systems. The question of simultaneity can only have a definite meaning in the case of the abruptly beginning storms, e.g. the positive equatorial storms ("S" storms), and perhaps the cyclo-median storms. The polar storms, on the other hand, usually set in gradually, and near the auroral zone, where they are strongest, they are of a very local character; sudden changes at one station may have no corresponding sudden change at another; but in the case of these polar storms (cf. Birkeland's work) it is often found that the centres of disturbance fields move slowly, usually along the auroral zone.

It has usually been assumed that the positive equatorial storms set in simultaneously all round the world. The question is very carefully examined in the work of Birkeland, referred to above, for the storm of January 26 , 1903. Looking at his figures, we notice that corresponding serrations show small differences in time at different stations, amounting to two or three minutes; but these differences are equally great for neighbouring stations as for more distant ones. The differences for neighbouring stations, which must be due to some error, are not so much caused by faults in the measurements on the time axis and the identification of corresponding points on the curves; they are rather to be considered as faults sticking to the magnetogram itself, for if we take out the time of several points of the disturbance, the time differences for corresponding points for two stations come out nearly constant.

Dr. R. L. Faris and Dr. Bauer, who have made a great amount of valuable work on the subject, have tried to eliminate the error by collecting neighbouring stations into groups, and then taking the difference between the average time of each group, and they arrive at the conclusion that the occurrence is not simultaneous. But so long as the differences between the groups are of the same order as the actual possible error of determination, it seems very dangerous to conclude to a non-simultaneity. Moreover, Mr. Krogness, by comparing the times of beginning of a number of storms at Potsdam with the corresponding times given by Dr. Faris for a group of stations on the western hemisphere, has found almost perfect simultaneity.

I think, then, that the present position of the question cannot be expressed in a better way than by the following statement taken from Prof. Birkeland's work:-

"We may conclude from this that the serrations appear simultaneously, or rather, the differences in time is less than the amount that can be detected by these registerings."

University of Christiania, January I4.

\section{Sir F. Galton and Composite Photography.}

MAY I be permitted, as an intimate friend of many years and under deep obligations to the late Sir Francis Galton, to say a word upon a matter which is perhaps not sufficiently emphasised? I refer to his very deep and lasting interest in composite photography, and his conviction of its scientific value. $\mathrm{He}$ considered it capable of and well worth systematic development. This was a frequent subject of conversation between us; and he told me many times (sometimes with reference to the original contributions to photography of my brother, Colonel Stuart Wortley) that he felt the method ought to be developed, not as a newspaper curiosity, but as a serious aid to sociology, and especially to the studv of heredity.

I'rof. Bowditch, of Harvard, told me that he found NO. 2 I 54 , VOL. 85$]$ an unaccountable indifference on the subject in America, while he entirely shared Galton's view of its possibilities.

If anyone could be found to take up the matter seriously there can be no doubt that the pioneer would be richly rewarded. In our last talk, a few weeks before his death, Sir Francis himself told me of really sensational results from the few experiments he was able to make with a comparatively primitive instrument. For instance, he told me he had collected photographs of Queen Victoria and Prince Albert and all their children. To his great surprise, the composite gave the likeness of Princess Alice and no one else. But this was only one of many equally suggestive results.

Duneaves, Harrow, February 3.

Darwin and the Transmission of Acquired Characters.

IT is difficult to understand how anyone well acquainted with Darwin's works can come to any other conclusion than that he firmly believed in Lamarck's principle of the transmission of characters acquired by use.

Two clear examples may be cited from "The Descent of Man " (second edition) :-

(I) "As the voice was used more and more the vocal organs would have been strengthened and perfected through the principle of the inherited effect of use" (p. 87).

(2) "There is no more improbability in the continued use of the mental and vocal organs leading to inherited changes in their structure and function, than in the case of handwriting, which depends partly on the form of the hand and partly on the disposition of the mind; and handwriting is certainly inherited" (p. 88).

In this matter Darwin was a true disciple of the great French naturalist to whom Prof. Judd refers with such scant respect.

January $3^{0}$.

E. A. PARKYN.

I REGRET that your correspondent should imagine that, in writing the words "poor old Lamarck," 1 showed "scant respect" for the great French naturalist. On the contrary, I desired to express the deep sympathy I felt for this grand pioneer in evolution, who, in old age and blind. ness, found his splendid achievements, for the time being, discredited by the work and arguments of his successful rival, Cuvier. In the little book which has given rise to this correspondence, I have insisted upon the splendid contributions of Lamarck, not only to botany and zoology, but also to geology, and have shown how the hostility towards his work, felt at first by Lyell and Darwin, was in the end modified, and his great merits acknowledged by both of them.

I quite agree with your correspondent that the passages he quotes-and many similar ones may be cited-show that Darwin accepted the Lamarckian views as to the transmission of acquired characters to a certain extent. Darwin's tendency was, however, to insist that individual variations were always "slight" or "exceedingly little," to use his own words In the passage to which reference has been made in the "Origin of Species," it would almost seem that he suggests that "variation" had been used in two different senses by authors-variations that could be transmitted and variations that could not be transmitted-and that he demurs to the distinction. I agree with Prof. Meldola, however, in thinking that, in all probability, the view put forward by Prof. Weismann in 1885 , that no acquired character is directly inherited, never fairly came under Darwin's consideration.

In discussing questions of this kind, it is important to realise, so far as is possible, what was the current opinion at the time Darwin wrote. Now Baron Cuvier, his brother Frederick, and their followers-whose writings so greatly influenced naturalists in the early years of the nineteenth century-all freely admitted the transmission, by inheritance, of acquired characters, habits, and instincts in domestic animals like dogs; what they denied was that any of the variations so transmitted, so far as the experience of 2000 years showed, were of a fundamental character.

That Darwin not only accepted the idea of the transmission of acquired characters, but even speculated on 